\title{
Design of type-1 servo controller for grid voltage modulated direct-power control of single-phase grid-connected PV inverter
}

\author{
Eyad Radwan', Mutasim Nour ${ }^{2}$, Ali Baniyounes ${ }^{3}$, Khalid S. Al-Olimat ${ }^{4}$ \\ ${ }^{1,3}$ Department of Electrical Engineering, Applied Science Private University, Jordan \\ ${ }^{2}$ School of Engineering and Physical Sciences, Heriot-Watt University, Dubai Campus, United Arab Emirates \\ ${ }^{4}$ Department of Electrical \& Computer Engineering and Computer Science, Ohio Northern University, United States
}

\begin{tabular}{l} 
Article Info \\
\hline Article history: \\
Received Aug 25, 2020 \\
Revised Oct 13, 2020 \\
Accepted Nov 1, 2020 \\
\hline Keywords: \\
Decoupled control \\
Direct power control \\
Grid-connected \\
Renewable energy \\
Single-phase inverter
\end{tabular}

Article Info

rticle history:

Received Aug 25, 2020

Revised Oct 13, 2020

Keywords:

Decoupled control

Grid-connected

Single-phase inverter

\begin{abstract}
This paper presents direct control of active and reactive power using grid voltage modulation for single-phase grid-connected photovoltaic inverter. A design of type-1 servo system based on pole-placement method is proposed to control the power flow using a simplified multiple-input multiple-output (MIMO) model of the system. Phase-locked loop (PLL) with a quarter cycle time delay is used to estimate the grid phase angle for the purpose of performing the stationary and synchronous reference frame transformation. Unipolar pulse width modulation (PWM) technique is used to control a single-phase inverter with $2.7 \mathrm{KVA}$ capacity connected to the photovoltaic system. The proposed controller can simply be tuned using minimum number of controller gains to achieve the transient and steady-state performance requirements. The proposed system, was capable of operating for a wide range of solar irradiance levels with a power factor in the range of 0.95 (leading/lagging), for the reactive power compensation purposes.
\end{abstract}

This is an open access article under the CC BY-SA license.

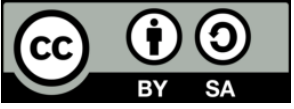

Corresponding Author:

Eyad Radwan

Department of Electrical Engineering

Applied Science Private University

Al Arab street, Amman, Jordan

Email: e_redwan@asu.edu.jo

\section{INTRODUCTION}

Renewable energy sources, especially photovoltaic powered systems, have been increasingly used as alternative sources of energy to power small residential and medium commercial installations. According to IEA forecast, renewable power capacity is set to expand by 50\% between 2019 and 2024, led by solar photovoltaic (PV). This increase of $1200 \mathrm{GW}$ is equivalent to the total installed power capacity of the United States today [1].

Solar photovoltaic systems are broadly classified into standalone PV systems and grid connected PV systems. Solar PV serves as a sole source of energy satisfying the load demand in standalone systems, whereas in grid connected PV systems, the AC grid also supports the occurring load demand [2]. Many of the single-phase PV systems operated in a standalone configuration, however, connecting them to grid have been on the rise due to the advantages, such as; providing ancillary services to the utility (reactive power support), load balancing, voltage support, and harmonic mitigation [3].

However, the increasing adoption of PV systems in a grid-connected configuration also poses more challenging issues $[4,5]$. This fact inspires the development of technologies and new researches to present and propose new solutions to allow the connection to the grid in a safe, reliable, and efficient ways. Recent research topics addressed techniques and improvements related to; synchronization of single-phase PV 
systems with the grid [6-8], various control methods to improve power quality such as: reduction of total harmonic distortion $[3,9]$, and reactive power injection strategies $[4,10]$ including low voltage ride through capabilities [11-16].

Converter control strategies such as grid voltage modulated direct power control (GVM-DPC) and DPC based on; sliding mode control (DPC-SMC), and space vector modulation (DPC-SVM) for three-phase grid-connected PV systems have been reported in literature [17]. Similarly, control strategies such as SMC [18], adaptive-fuzzy SMC [19], and Adaptive Intelligent SMC [20] are also implemented to control single-phase grid-connected PV systems.

Control strategies for single-phase grid-connected PV inverter follow similar strategies adopted in three-phase systems with a slight difference in creating the quadrature voltage vector. However, once the quadrature voltage signal is generated, conventional control of active and reactive power using the concept of vector current control can be implemented in a similar manner to three-phase systems. Conventional control methods implementing either, proportional resonant (PR) controllers in stationary $\alpha \beta$ or proportional integral (PI) controllers in rotating DQ reference frames are both widely employed for grid connected power converters, and both strategies are able to provide a zero steady state error [21].

This paper proposes a design of a controller for single-phase PV system based on the GVM-DPC method using servo type-1 controllers for active and reactive power regulation instead of traditional PI controllers. The inverter-grid system is modelled first as MIMO system in state space with coupling exists between states. However, decoupling between input and output is achieved since the system is represented in the DQ reference frame. Coupling between the states is also removed by proper selection of the controller gain using the pole-placement method. The paper is structured as follows; modelling of the system, design of the controller, design of L filter and maximum power tracking point (MPPT) are given in the research method section, the simulation results of the proposed controller are presented in the results and discussion section, and conclusion is given the last section.

\section{RESEARCH METHOD}

In this section the state space model of active and reactive power in a single-phase grid-connected inverter is developed based on the earlier work presented in [17]. Figure 1 shows the block structure of the system under investigation. The system consists of PV modules capable of delivering $2.7 \mathrm{kWp}$, single-phase $\mathrm{H}$ bridge inverter, $\mathrm{L}$ filter with impedance $\left(r_{f}+j \omega L_{f}\right)$, grid model with its equivalent impedance $\left(z_{g}\right)$. The processing and control unit is tasked with the estimation of the grid phase angle using PLL (using the quarter cycle time delay concept), signal transformation stationary $(\alpha \beta)$ and synchronous $(D Q)$ reference frames, calculation of reference active power, and MPPT using the perturb and observe (P\&O) algorithm. The processing and control unit is also tasked with executing the control algorithms to generate the inverter reference signal $\left(v_{\text {ref }}\right)$ which in turn is used by a unipolar PWM unit to control the inverter to track the commanded signals.

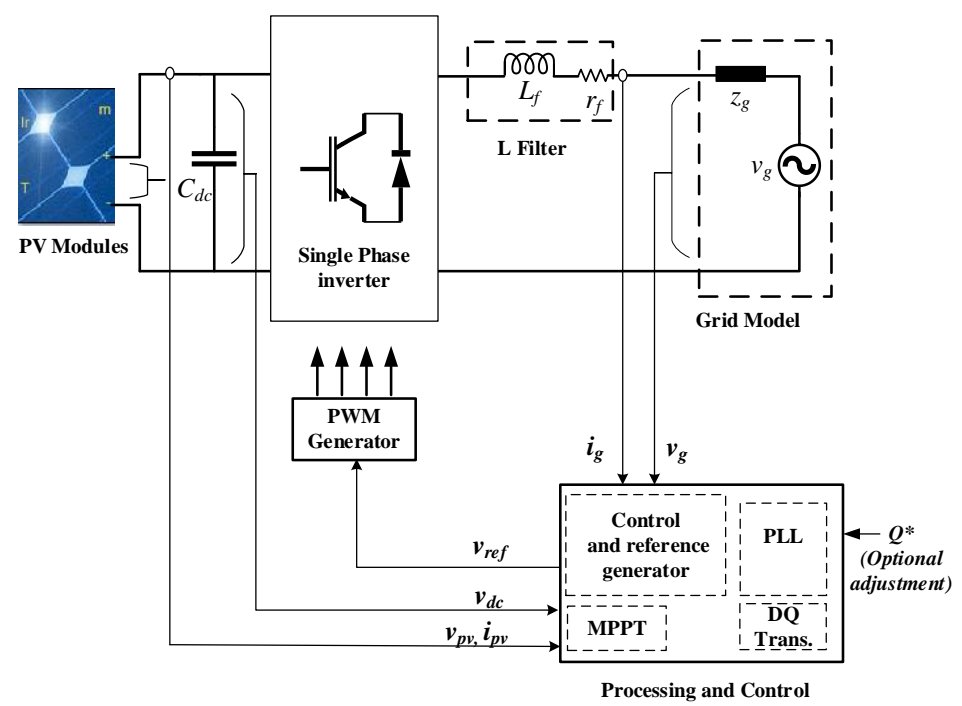

Figure 1. Block diagram of single-phase grid connected PV system 


\subsection{DQ model of grid-connected inverter}

Figure 2(a) shows a simplified equivalent circuit of single-phase grid-connected inverter. From the equivalent circuit, the relationship between the inverter voltage, grid voltage and grid current can be written using Kirchhoff's Voltage Law (1);

$$
v_{i}=r_{f} i_{g}+L_{f} \frac{d}{d t} i_{g}+v_{g}
$$

where, $v_{i}$ is the inverter voltage, $v_{g}$ is the grid voltage, $i_{g}$ is the grid current, and $r_{f}$ and $L_{f}$ are the filer equivalent resistance and inductance, respectively. Using the vector space representation in Figure 2(b), (1) can be expressed in the stationary reference frame $(\alpha \beta)$ as shown in (2);

$$
v_{i \alpha \beta}=r_{f} i_{g \alpha \beta}+L_{f} \frac{d}{d t} i_{g \alpha \beta}+v_{g \alpha \beta}
$$

where, $v_{i \alpha \beta}$ and $v_{g \alpha \beta}$ indicate the inverter and grid voltages, $i_{g \alpha \beta}$ indicates the grid currents all in the $\alpha \beta$ reference frame. As shown in (2) is further transformed to the synchronous reference frame $(D Q)$, which is rotating at the grid angular frequency, to converter the model equation into a linear time invariant (LTI) model. With the direct axis $(D)$ of the synchronous reference frame aligned with the grid voltage vector, then (2) can be expressed as,

$$
v_{i D}=r_{f} i_{g D}+L_{f} \frac{d}{d t} i_{g D}-\omega L i_{g Q}+v_{g D}
$$

and,

$$
v_{i Q}=r_{f} i_{g Q}+L_{f} \frac{d}{d t} i_{g Q}+\omega L i_{g D}+v_{g Q}
$$

where, $v_{i D}, v_{i Q}, v_{g D}$, and $v_{g Q}$, indicate the inverter and grid voltages, $i_{g D}$, and $i_{g Q}$ indicate the grid currents all are represented in the $D Q$ reference frame, and $\omega$ indicates the angular frequency of the grid.

Since the $D$ axis of the synchronous reference frame is aligned with the grid voltage, the grid voltages in the $D Q$ reference frame become, $v_{g D}=V_{g}$ and $v_{g Q}=0$. Hence (3) can be simplified to,

$$
v_{i D}=r_{f} i_{g D}+L_{f} \frac{d}{d t} i_{g D}-\omega L i_{g Q}+V_{g}
$$

and,

$$
v_{i Q}=r_{f} i_{g Q}+L_{f} \frac{d}{d t} i_{g Q}+\omega L i_{g D}
$$

The instantaneous active and reactive power for single-phase inverter in the DQ reference frame are given as [4],

$$
P=\frac{1}{2}\left(v_{g D} i_{g D}+v_{g Q} i_{g Q}\right)
$$

and,

$$
Q=\frac{1}{2}\left(v_{g Q} i_{g D}-v_{g D} i_{g Q}\right)
$$

where $P$ and $Q$ are the active and reactive powers of the inverter, respectively. Since $v_{g D}=V_{g}$ and $v_{g Q}=0$, (5) and (6) can be reduced to,

$$
P=\frac{1}{2} V_{g} i_{g D}
$$

and,

$$
Q=-\frac{1}{2} V_{g} i_{g Q}
$$


The instantaneous variation of the active and reactive powers can be obtained by differentiating (7) and (8) with respect to time. Assuming that the grid voltage is constant, then,

$$
\frac{d}{d t} P=\frac{1}{2} V_{g} \frac{d}{d t} i_{g D}
$$

and,

$$
\frac{d}{d t} Q=-\frac{1}{2} V_{g} \frac{d}{d t} i_{g Q}
$$

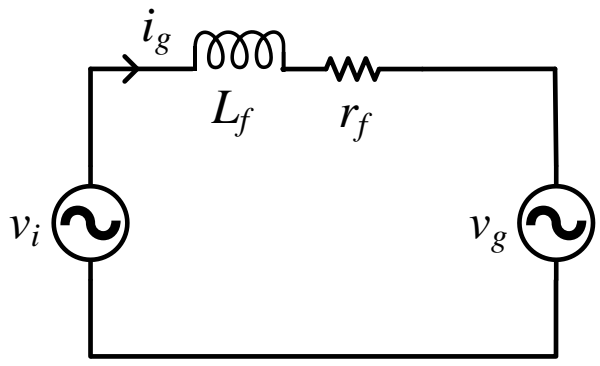

(a)

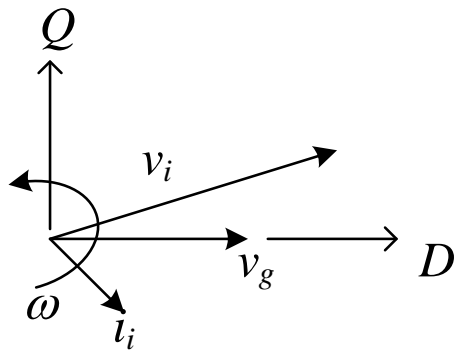

(b)

Figure 2. Model of single-phase grid-connected inverter, (a) equivalent circuit, (b) vector space representation

Substituting (4a) into (9),

$$
\frac{d}{d t} P=\frac{1}{2}\left(-\frac{r_{f}}{L_{f}} V_{g} i_{g D}+\omega V_{g} i_{g Q}+\frac{1}{L_{f}} V_{g} v_{i D}-\frac{1}{L_{f}} V_{g}^{2}\right)
$$

As shown in (11) can further be simplified as,

$$
\frac{d}{d t} P=-\frac{r_{f}}{L_{f}} P-\omega Q+\frac{1}{2 L_{f}} V_{g}\left(v_{i D}-V_{g}\right)
$$

or,

$$
\frac{d}{d t} P=-\frac{r_{f}}{L_{f}} P-\omega Q+\frac{1}{2 L_{f}}\left(v_{D}-V_{g}^{2}\right)
$$

similarly, from (4b) and (10),

$$
\frac{d}{d t} Q=\omega P-\frac{r_{f}}{L_{f}} Q-\frac{1}{2 L_{f}} v_{Q}
$$

From (12) and (13) a state space model for the single-phase grid-connected inverter can be developed as,

$$
\left[\begin{array}{c}
\dot{P} \\
\dot{Q}
\end{array}\right]=\left[\begin{array}{cc}
-\frac{r_{f}}{L_{f}} & -\omega \\
\omega & -\frac{r_{f}}{L_{f}}
\end{array}\right]\left[\begin{array}{l}
P \\
Q
\end{array}\right]+\left[\begin{array}{cc}
\frac{1}{2 L_{f}} & 0 \\
0 & \frac{-1}{2 L_{f}}
\end{array}\right]\left[\begin{array}{c}
v_{D} \\
v_{Q}
\end{array}\right]+\left[\begin{array}{c}
\frac{-1}{2 L_{f}} \\
0
\end{array}\right] V_{g}^{2}
$$

where, $\left[\begin{array}{ll}P & Q\end{array}\right]^{T}$ is the state vector, $\left[\begin{array}{ll}v_{D} & v_{Q}\end{array}\right]^{T}$ is the input vector, $\left[\begin{array}{ll}\frac{-1}{2 L_{f}} & 0\end{array}\right]^{T}$ is disturbance vector, $v_{D}=V_{g} v_{i D}$, and $v_{Q}=V_{g} v_{i Q}$. The output equation can also be written as,

$$
\left[\begin{array}{l}
y_{1} \\
y_{2}
\end{array}\right]=\left[\begin{array}{ll}
1 & 0 \\
0 & 1
\end{array}\right]\left[\begin{array}{l}
P \\
Q
\end{array}\right]
$$


The system in (14) presents a second order, two-input, two-output system with coupling between the two states and disturbance input. The signal flow graph (SFG) as in Figure 3 shows the representation of the system in (14).

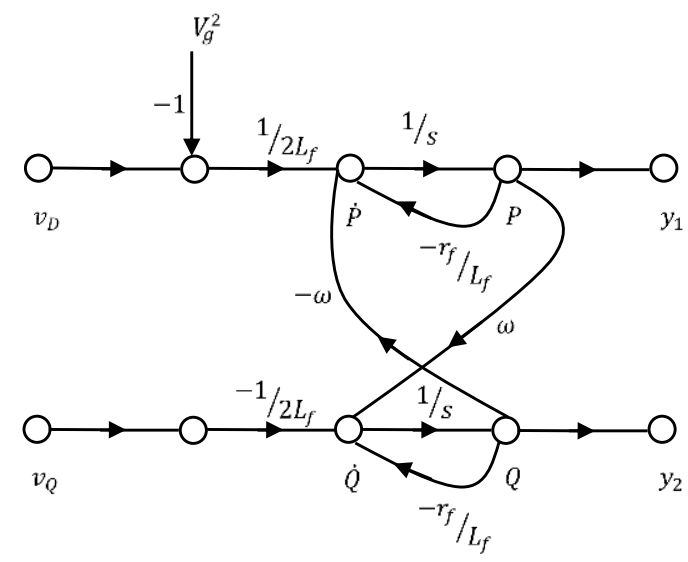

Figure 3. Signal flow graph representation of single-phase grid-connected inverter

\subsection{Design of type- 1 servo system}

In this subsection the approach to using the pole placement in designing type- 1 servo systems is explained. The general structure for the pole placement approach to type-1 servo system is shown in Figure 4 [22]. The same approach in Figure 4 has been applied to the system in Figure 3. The states, $P$ and $Q$, are used as state feedback signals to the inputs $v_{D}$ and $v_{Q}$, and the outputs of the system, $y_{1}$ and $y_{2}$, are used as feedback signals to the controller inputs. Figure 5 shows the SFG of the controller and the grid-inverter system.

The state space representation of the controller can be written from Figure 5, and is given as in (15). The system in (15) is fourth order and there are six unknown controller gains.

$$
\left[\begin{array}{c}
\dot{e}_{1} \\
\dot{P} \\
\dot{e}_{2} \\
\dot{Q}
\end{array}\right]=\left[\begin{array}{cccc}
0 & -1 & 0 & 0 \\
\frac{k_{11}}{2 L_{f}} & -\left(\frac{k_{12}}{2 L_{f}}+\frac{r_{f}}{L_{f}}\right) & 0 & -\left(\frac{k_{13}}{2 L_{f}}+\omega\right) \\
0 & 0 & 0 & -1 \\
0 & \left(\frac{k_{23}}{2 L_{f}}+\omega\right) & \frac{-k_{21}}{2 L_{f}} & \left(\frac{k_{22}}{2 L_{f}}-\frac{r_{f}}{L_{f}}\right)
\end{array}\right]\left[\begin{array}{c}
e_{1} \\
P \\
e_{2} \\
Q
\end{array}\right]+\left[\begin{array}{ll}
1 & 0 \\
0 & 0 \\
0 & 1 \\
0 & 0
\end{array}\right]\left[\begin{array}{l}
P_{r} \\
Q_{r}
\end{array}\right]
$$

where, $P_{r}$ and $Q_{r}$, respectively indicate the reference active and reactive power commands.

The gains $k_{13}$ and $k_{23}$, can be selected to eliminate the states cross-coupling terms. Therefore, both gains can be set as in (16).

$$
k_{13}=k_{23}=-2 \omega L_{f}
$$

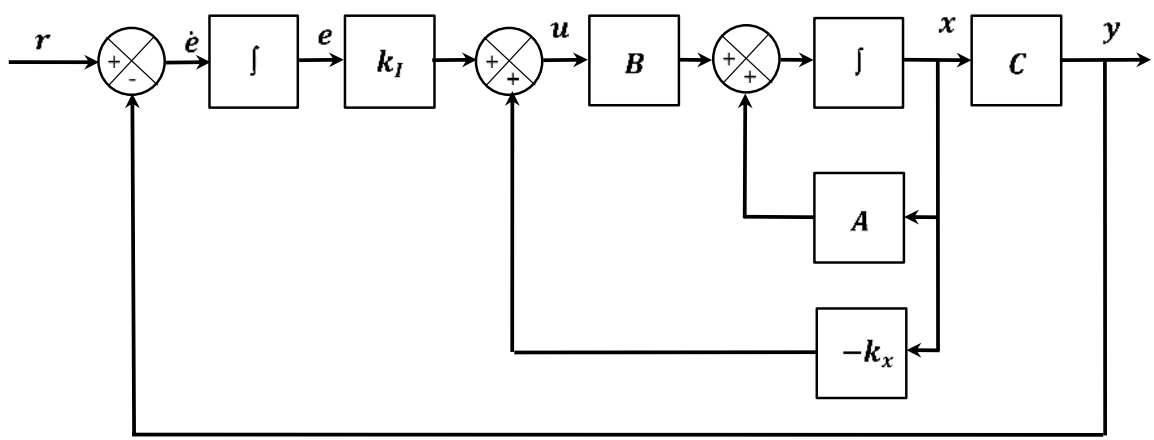

Figure 4. General structure of pole placement for type-1 servo system design 


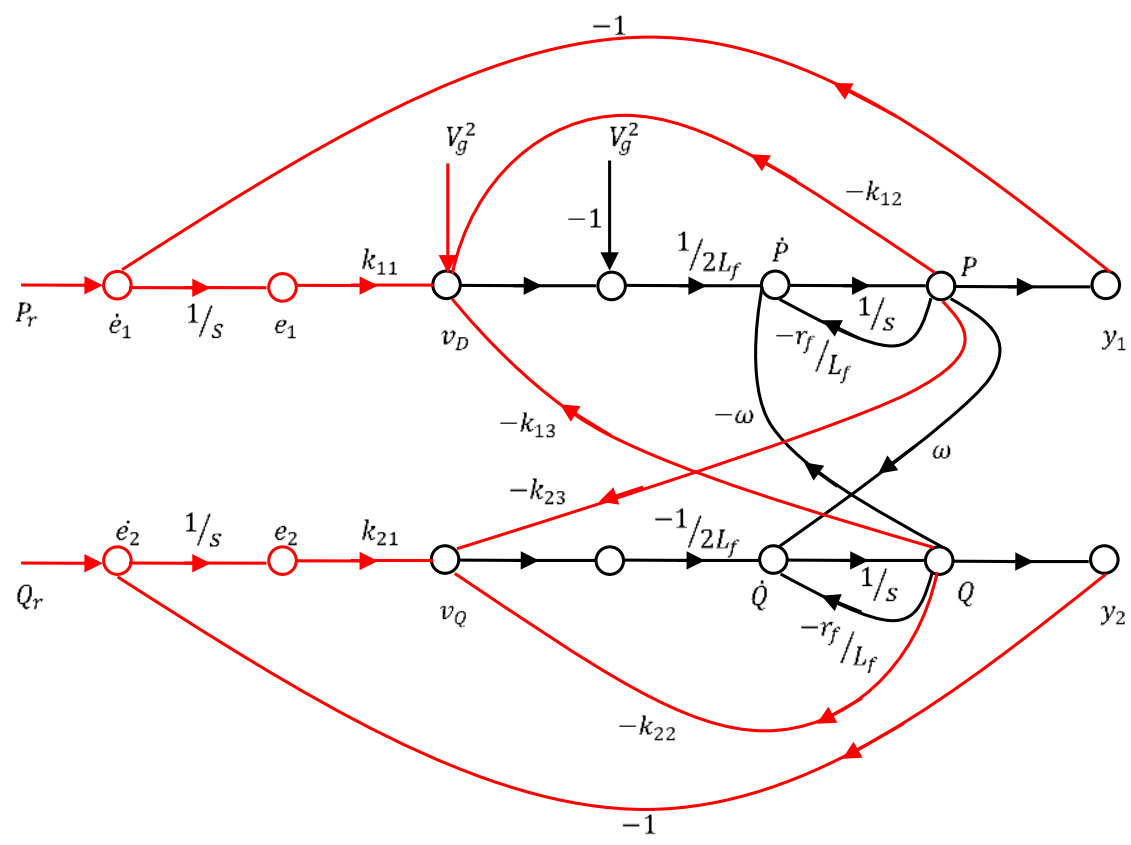

Figure 5. Type-1 servo system state controller for grid-connected single-phase inverter

Once the states are decoupled by proper selection of the gains $k_{13}$ and $k_{23}$, the multi-input, multioutput can be easily decomposed into two second-order SISO systems; one for active power $(P)$ and the other for reactive power $(Q)$. Each of the two SISO second order systems will result in two unknowns to be designed. The state space equation for the active power $(P)$ can be written as (17),

$$
\left[\begin{array}{c}
\dot{e}_{1} \\
\dot{P}
\end{array}\right]=\left[\begin{array}{cc}
0 & -1 \\
\frac{k_{11}}{2 L_{f}} & -\left(\frac{k_{12}}{2 L_{f}}+\frac{r_{f}}{L_{f}}\right)
\end{array}\right]\left[\begin{array}{c}
e_{1} \\
P
\end{array}\right]+\left[\begin{array}{l}
1 \\
0
\end{array}\right] P_{r}
$$

From (17), the closed-loop transfer function for the active power controller can be written as (18),

$$
\left[\begin{array}{c}
\dot{e_{1}} \\
\dot{P}
\end{array}\right]=\left[\begin{array}{cc}
0 & -1 \\
\frac{k_{11}}{2 L_{f}} & -\left(\frac{k_{12}}{2 L_{f}}+\frac{r_{f}}{L_{f}}\right)
\end{array}\right]\left[\begin{array}{l}
e_{1} \\
P
\end{array}\right]+\left[\begin{array}{l}
1 \\
0
\end{array}\right] P_{r}
$$

The gains $k_{11}$ and $k_{12}$ can then be designed to achieve the desired response according to standard second order system specifications such as (19) and (20);

$$
\frac{k_{11}}{2 L_{f}}=\omega_{n}^{2}
$$

and,

$$
\frac{k_{12}}{2 L_{f}}+\frac{r_{f}}{L_{f}}=2 \zeta \omega_{n}
$$

where, $\omega_{n}$ and $\zeta$ indicate respectively, the undamped natural frequency and damping ratio of a standard second order system.

Similarly, the closed-loop transfer function for the reactive power controller can be written as (21),

$$
\left[\begin{array}{c}
\dot{e_{2}} \\
\dot{Q}
\end{array}\right]=\left[\begin{array}{cc}
0 & -1 \\
\frac{-k_{21}}{2 L_{f}} & \left(\frac{k_{22}}{2 L_{f}}-\frac{r_{f}}{L_{f}}\right)
\end{array}\right]\left[\begin{array}{l}
e_{2} \\
Q
\end{array}\right]+\left[\begin{array}{l}
1 \\
0
\end{array}\right] Q_{r}
$$

and from (21), the closed-loop transfer function of the reactive power can be given as (22), 


$$
\frac{Q(s)}{Q_{r}(s)}=\frac{-k_{21} / 2 L_{f}}{s^{2}-\left(\frac{k_{22}}{2 L_{f}}-\frac{r_{f}}{L_{f}}\right) s-\frac{k_{21}}{2 L_{f}}}
$$

again, the gains $k_{21}$ and $k_{22}$ can be designed based on desired second order system specifications.

\subsection{Design of $L$ filter and MPPT}

An $\mathrm{L}$ filter is used to reduce the high-order current harmonics produced by the inverter at switching frequency. The L filter is designed using the methodology presented in [23]. The maximum value of the filter total inductance $\left(L_{f \max }\right)$ is given as,

$$
L_{f \max }=\frac{v_{g}^{2}}{2 \pi f P} \times 10 \%
$$

where, $v_{g}$ and $f$ indicate respectively the grid voltage and frequency, and $P$ is the power of the inverter. However, to achieve an acceptable current THD at low power levels this requires an increase in the value of the filter inductor, thus (23) is applied at half the inverter rated power.

To guarantee that maximum power is being extracted from a PV array and transferred to grid/ load system at all times, MPPT control algorithms are usually used for this purpose. In recent years, a large number of MPPT techniques have been proposed for tracking the maximum power point. Proposed techniques vary in terms of complexity, accuracy, efficiency, and hardware requirements. Classical MPPT techniques such as; perturb and observe $(\mathrm{P} \& \mathrm{O})$, incremental conductance (IC), and ripple correlation (RC) methods are deemed to be suitable and practical [24].

In this study $\mathrm{P} \& \mathrm{O}$ technique is used to the track the maximum power point of a PV array. The array used in this study is configured using one parallel string with 12 series-connected modules per string. The I-V and P-V characteristics of the PV array for different levels of solar irradiance and under a constant temperature of $25^{\circ} \mathrm{C}$ are shown in Figures 6(a) and 6(b), respectively.

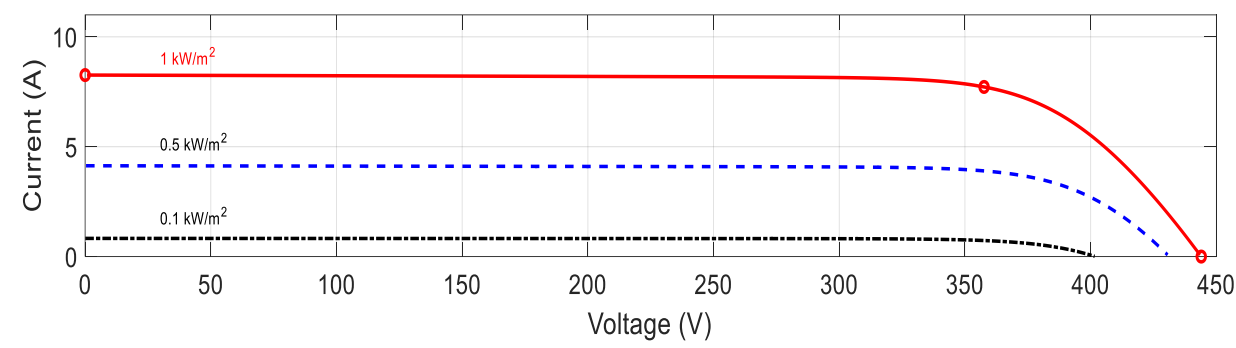

(a)

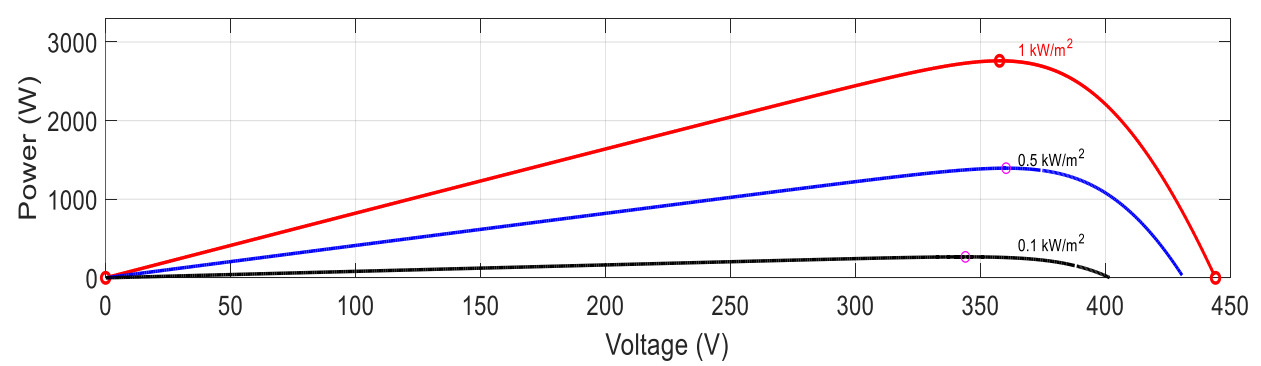

(b)

Figure 6. Photovoltaic array characteristics: (a) I-V characteristics for varying irradiance (b) P-V characteristics for varying irradiance

\section{RESULTS AND DISCUSSION}

To demonstrate the effectiveness of the proposed controller, a simulation study has been carried out using MATLAB/Simulink. The parameters of the grid-inverter system are listed in Table 1 . In the first test the grid-inverter system is simulated for a step change in solar irradiance from 900 to $500 \mathrm{~W} / \mathrm{m}^{2}$ while 
supplying zero reactive power. Figure 7 shows the amount of active power supplied to the grid is $2400 \mathrm{~W}$ when the irradiance is at $900 \mathrm{~W} / \mathrm{m}^{2}$, then the power drops to approximately $1390 \mathrm{~W}$, when the irradiance drops to $500 \mathrm{~W} / \mathrm{m}^{2}$ with zero reactive power is being supplied to the grid. The steady state performance shows and acceptable level of power ripples. The voltage and current signals are shown in Figure 8 and the corresponding level of current THD is shown in Figure 9. The current THD as shown in Figure 9 of the output current conforms with the required standards $(<5 \%)$ as stated in EN 50160 and IEEE1547 standards [3, 24]. It can be observed that the current THD has increased slightly but stayed within the prescribed limits $(<5 \%)$; which is one of the major drawbacks reported for low levels of solar irradiance [25, 26].

Table 1. System parameters used in simulation

\begin{tabular}{cccc}
\hline Parameter & Value & Parameter & Value \\
\hline Inverter rated power $($ Srated) & $2.7 \mathrm{kVA}$ & PWM Switching frequency $(\mathrm{fs})$ & $10 \mathrm{kHz}$ \\
Filter inductances $\left(L_{f}\right)$ & $10.0 \mathrm{mH}$, & Grid voltage $V_{g}$ & $230 \mathrm{~V}$ \\
Grid side inductance $\left(L_{g}\right)$ & $3 \mathrm{mH}$ & Grid frequency $\left(f_{g}\right)$ & $50 \mathrm{~Hz}$ \\
Grid side resistance $\left(r_{g}\right)$ & $1.0 \Omega$ & Controller gains $K_{l 1}$, and $K_{2 l}$ & 260 \\
DC link Capacitor $\left(C_{d c}\right)$ & $2500 \mu \mathrm{F}$ & Controller gains $K_{l 2}$, and $K_{22}$ & 5 \\
\hline
\end{tabular}

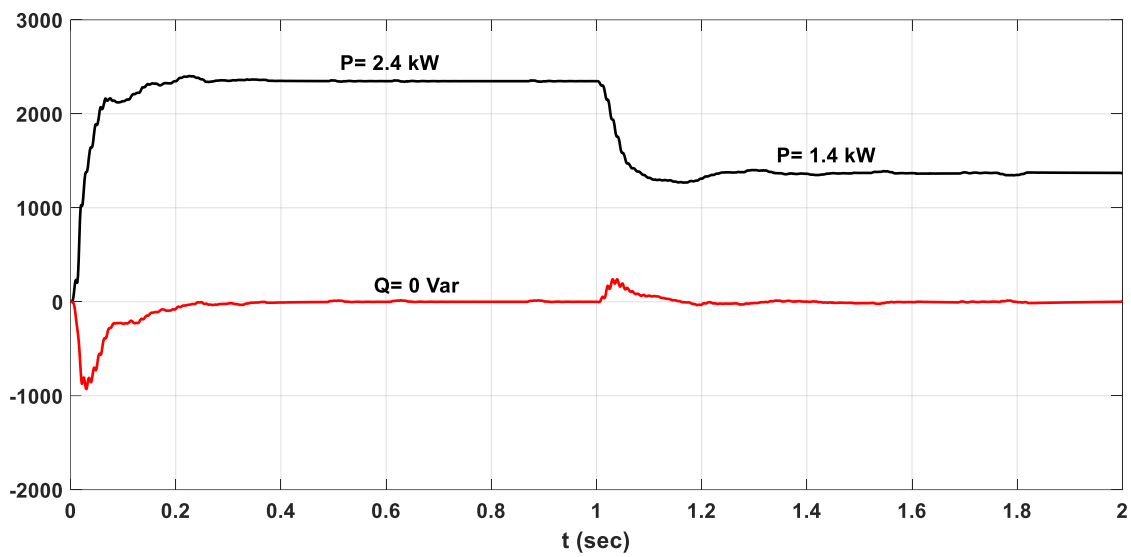

Figure 7. Simulation results of grid active and reactive power responses when the irradiance level is changed from 900 to $500 \mathrm{~W} / \mathrm{m}^{2}$ while operating at unity $\mathrm{PF}$

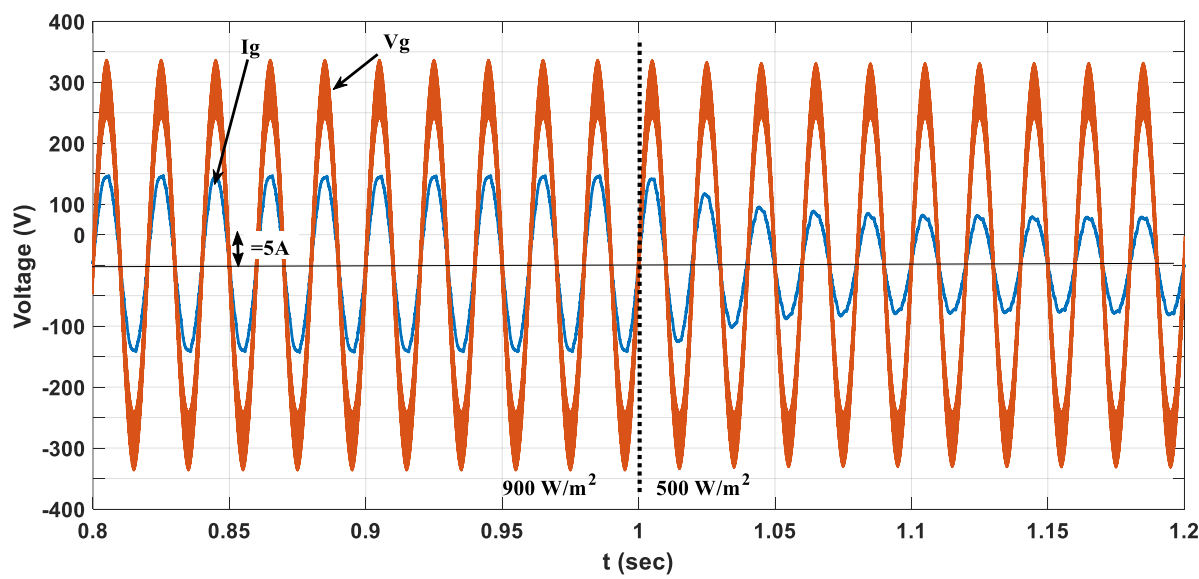

Figure 8 . Grid voltage and current when the irradiance level is changed from 900 to $500 \mathrm{~W} / \mathrm{m}^{2}$

In the second test, the level of solar irradiance is fixed at $500 \mathrm{~W} / \mathrm{m}^{2}$, while the reference reactive power is changed from -456 to 456 Var (leading to lagging PF at 0.95 ). This mode of operation shows the capability of the PV inverter system of providing ancillary services to the grid (reactive power support). Figure 10 shows the active and reactive power flow. Figure 11 shows the voltage and current signals, and 
Figure 12 shows the current THD. It can be observed that the current THD level has slightly increased when the inverter is supplying reactive power to the grid, this can be justified due to the increase in the modulation index of the PWM inverter to allow injection of reactive power into the grid.

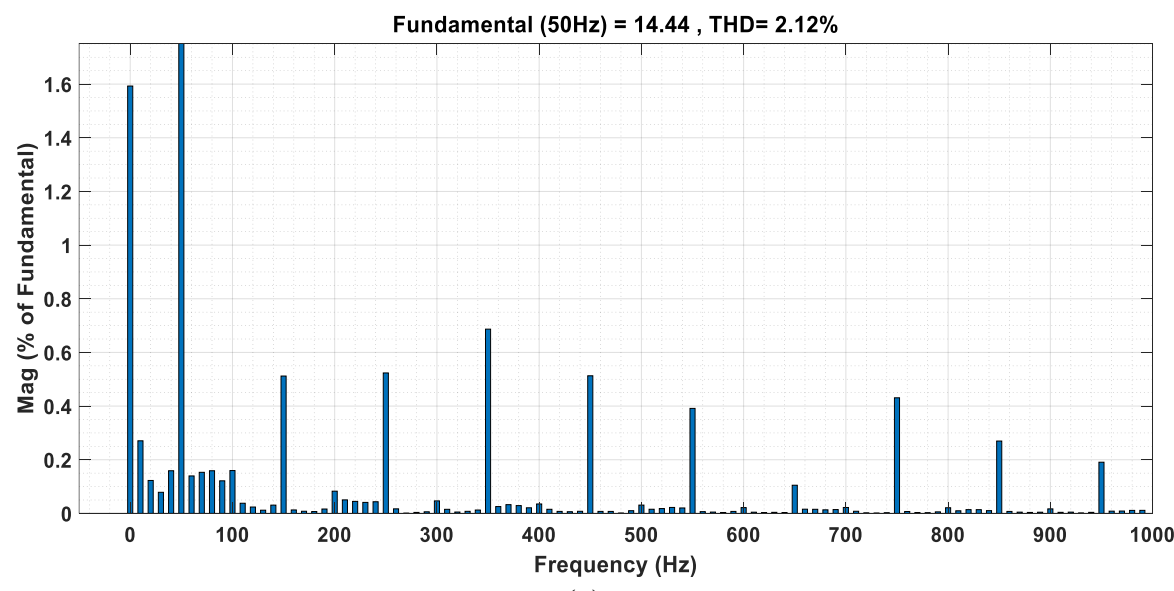

(a)

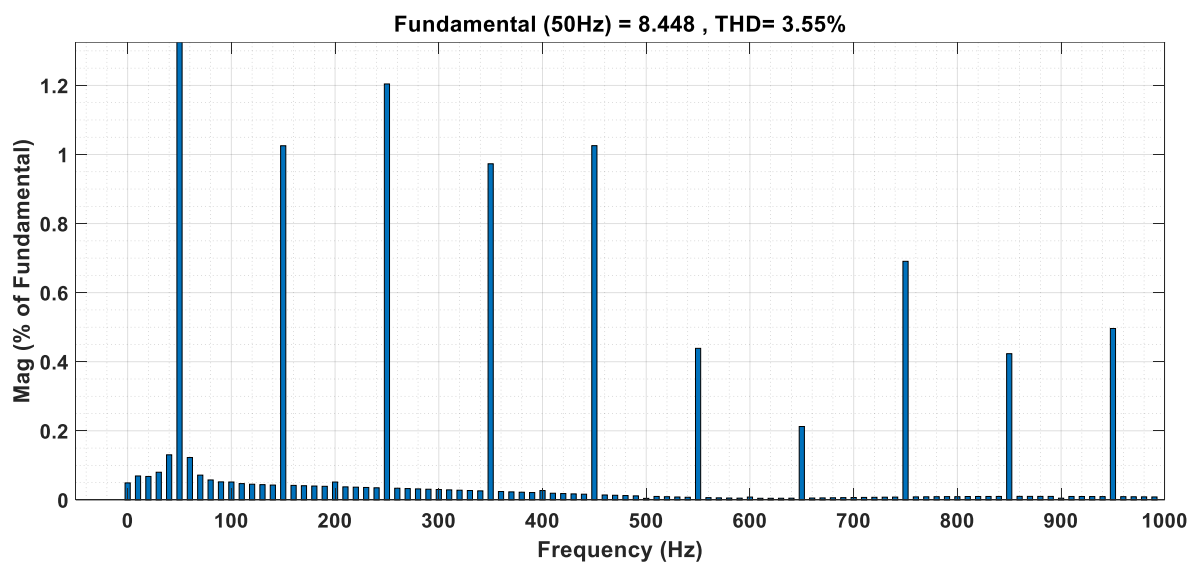

(b)

Figure 9. Output current THD for irradiance levels of (a) $900 \mathrm{~W} / \mathrm{m}^{2}$ and (b) $500 \mathrm{~W} / \mathrm{m}^{2}$

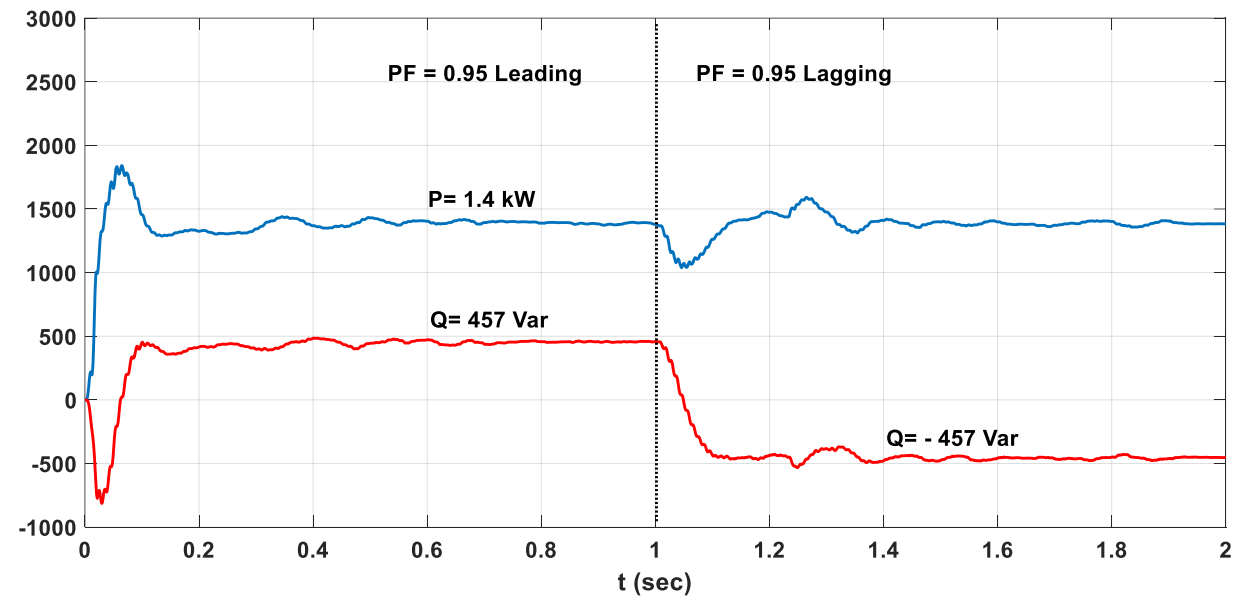

Figure 10. Simulation results of grid active and reactive power responses when the irradiance level is fixed at $500 \mathrm{~W} / \mathrm{m}^{2}$ while operating at $0.95 \mathrm{PF}$ (leading/lagging) 


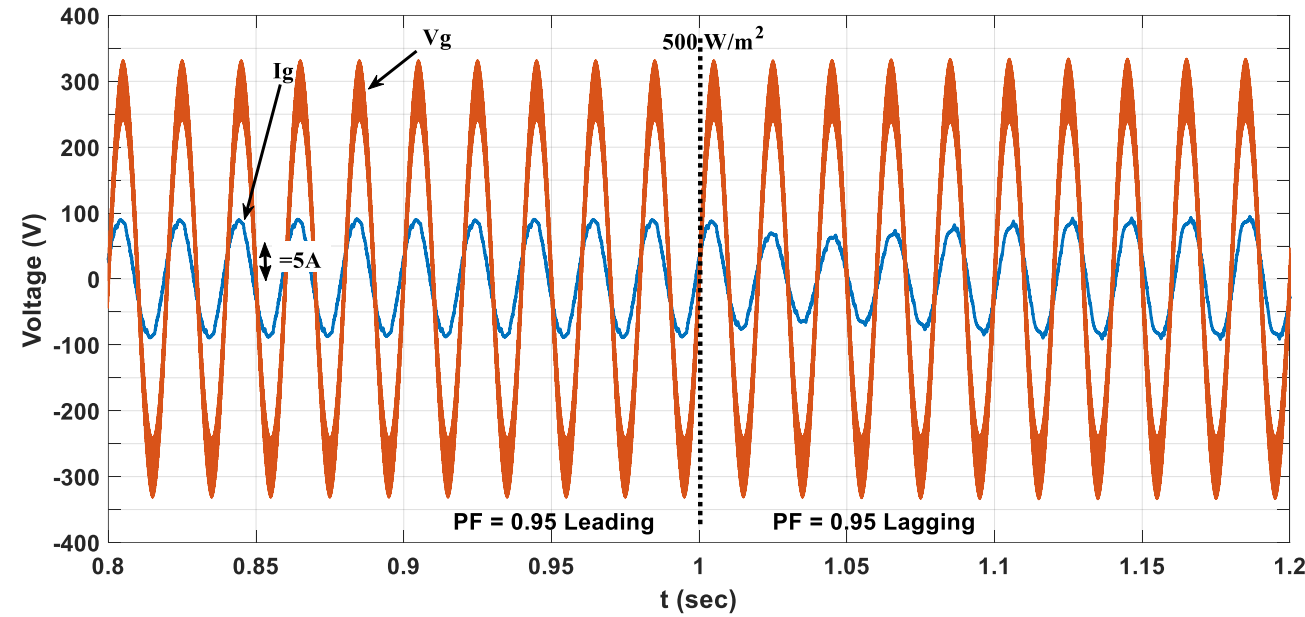

Figure 11. Grid voltage and current when the irradiance level is fixed at $500 \mathrm{~W} / \mathrm{m}^{2}$ while operating at $0.95 \mathrm{PF}$ (leading/lagging)

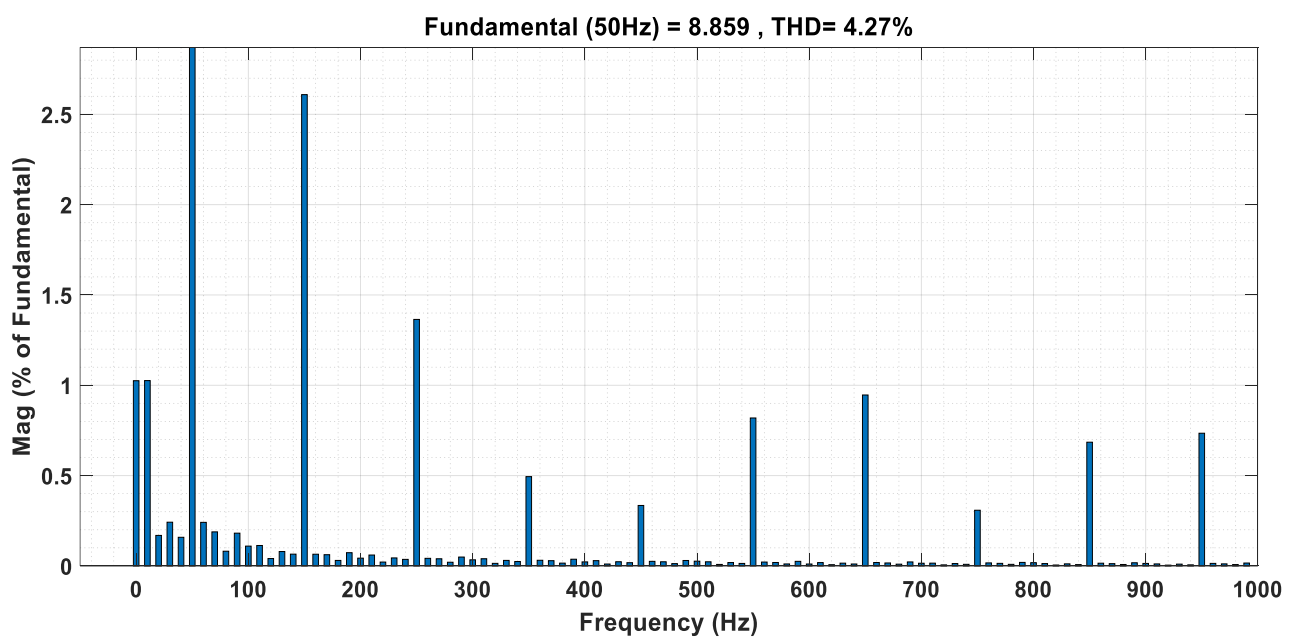

(a)

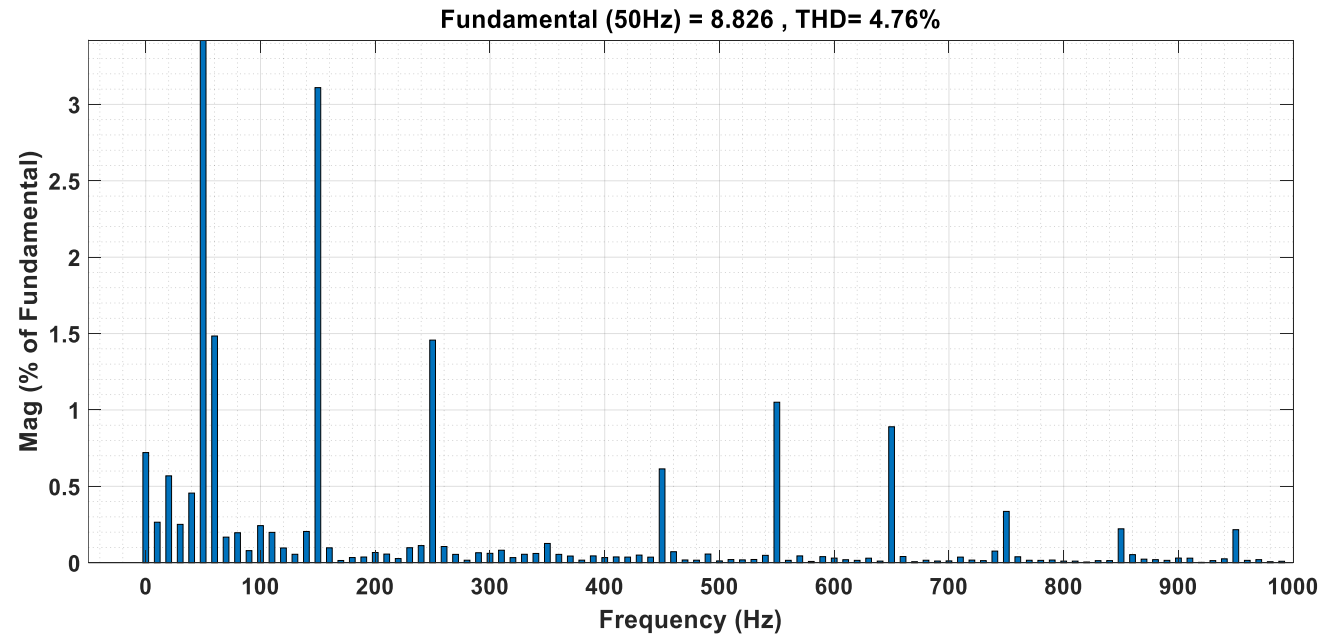

(b)

Figure 12. Output current THD for irradiance levels of $500 \mathrm{~W} / \mathrm{m}^{2}$ (a) $0.95 \mathrm{PF}$ leading and (b) 0.95 lagging 


\section{CONCLUSION}

In this study the operation of a single-phase grid-connected PV inverter system has been examined when controlled using type-1 servo system based on pole-placement method. A simple tuning method for the controller gains has been proposed in this study to eliminate the coupling that exists between the active and reactive power control loops, and also to achieve acceptable transient and steady state performances. The controller has been used to directly regulate inverter's active and reactive power flow. The PV inverter has been operated with a flexible reactive power compensation mode to provide ancillary services to the grid. This compensation scheme becomes very useful when it is triggered by the voltage level at the PCC, or alternatively used to comply with reactive power demands set by the grid operator. The simulation results showed that when the solar irradiance is at full level, the THD of the grid-injected current conforms with required standards. However, for low levels of solar irradiance, the THD in the grid-injected current increased slightly, but stayed within the prescribed limits.

\section{ACKNOWLEDGEMENTS}

The researchers are grateful to the Applied Science Private University (ASU) Amman, Jordan for the full financial support grated to this research project.

\section{REFERENCES}

[1] "IEA website," 2020. [Online]. Available: https://www.iea.org/fuels-and-technologies/.

[2] S. Sundaram, et al., "Grid Connected Photovoltaic Systems: Challenges and Control Solutions-A Potential Review," International Journal of Electronics and Electrical Engineering, vol. 4, no. 6, pp. 463-473, 2016.

[3] V. Beena, et al., "Active and Reactive Power Control of Single Phase Transformerless Grid Connected Inverter for Distributed Generation System," International Journal of Applied Engineering Research, vol. 13, no. 1, pp. 150-157, 2018.

[4] Y. Yang, et al., "Reactive Power Injection Strategies for Single-Phase Photovoltaic Systems Considering Grid Requirements," IEEE Transactions on Industry Applications, vol. 50, no. 6, pp. 4065-4076, 2014.

[5] A. M. Baniyounes, "Renewable energy potential in Jordan," International Journal of Applied Engineering Research, vol. 12, no. 19, pp. 8323-8331, 2017.

[6] E. Radwan, et al., "Modified Phase Locked Loop for Grid Connected Single Phase Inverter," International Journal of Electrical and Computer Engineering (IJECE), vol. 9, no. 5, pp. 3934-3943, 2019.

[7] F. Xiao, et al., "A Novel Open-Loop Frequency Estimation Method for Single-Phase Grid Synchronization Under Distorted Conditions," IEEE Journal of Emerging and Selected Topics in Power Electronics, vol. 5, no. 3, pp. 1287-1297, 2017.

[8] L. Hadjidemetriou, et al., "A Synchronization Scheme for Single-Phase Grid-Tied Inverters under Harmonic Distortion and Grid Disturbances," IEEE Transactions on Power Electronics, vol. 32, no. 4, pp. 2784-2793, 2017.

[9] M. Prodanovic, et al., "Harmonic and Reactive Power Compensation as Ancillary Services in Inverter Based Distributed Generation," IET Generation, Transmission \& Distribution, vol. 1, no. 3, pp. 432-438, 2007.

[10] G. M. Tina and G. Celsa, "Active and Reactive Power Regulation in Grid-Connected PV Systems," 2015 50th International Universities Power Engineering Conference (UPEC), Stoke on Trent, 2015, pp. 1-6.

[11] E .Radwan, et al., "Fuzzy Logic Control for Low-Voltage Ride-Through Single-Phase Grid-Connected PV Inverter," Energies, vol. 12, no. 24, p. 4796, 2019.

[12] S. Sadat and J. Patel, "A Review of Low Voltage Ride-Through Capability Techniques for Photovoltaic Power Plant Systems," International Journal of Innovative Science and Modern Engineering (IJISME), vol. 5, pp. 633-640, 2019.

[13] A. Benali, et al., "M. Power Quality Improvement and Low Voltage Ride Throught Capability in Hybrid Wind-PV Farms Grid-Connected Using Dynamic Voltage Restorer,” IEEE Access, vol. 6, pp. 68634-68648, 2018.

[14] Y. Sravanthi and P. Sujatha, "Fuzzy Logic Controller for Low Voltage Ride through Capability Improvement of Grid Connected Photovoltaic Power Plants," International Journal of Advanced Research in Electrical, Electronics and Instrumentation Engineering, vol. 6, no. 9, pp. 7213-7226, 2017.

[15] K. Li, et al., "Research on Low Voltage Ride Through of the Grid-Connected PV System," In Proceedings of the International Conference on Advances in Energy, Environment and Chemical Engineering, 2015, Changsha, China, 2015.

[16] Y. Yang and F. Blaabjerg, "Low-Voltage Ride-Through Capability of a Single-Stage Single-Phase Photovoltaic System Connected to the Low-Voltage Grid," International Journal of Photoenergy, vol. 2013, no. 1, pp. 1-9, 2013.

[17] Y. Gui, et al., "Control of Grid-connected Voltage-Source Converters: The relationship between Direct-Power Control and Vector-Current Control," IEEE Industrial Electronics Magazine, vol. 13, no. 2, pp. 31-40, 2019.

[18] J. Fei and Y. Zhu, "Adaptive Fuzzy Sliding Control of Single-Phase PV Grid-Connected Inverter," PLOS ONE, vol. 12, no. 8, 2017.

[19] S. A. A. Fallahzadeh, et al., "Sliding Mode Control of Single Phase Grid Connected PV System Using Sign Function," 2017 IEEE 4th International Conference on Knowledge-Based Engineering and Innovation (KBEI), Tehran, 2017, pp. 0391-0397.

[20] Y. Fang et al., "Adaptive Intelligent Sliding Mode Control of a Photovoltaic Grid-Connected Inverter," Applied Sciences, vol. 8, no. 10, p. 1756, 2018. 
[21] W. Zhang, et al., "A Proportional Resonant Controller Tuning Method for Grid connected Power Converters with LCL+trap Filter," 2014 International Conference on Renewable Energy Research and Application (ICRERA), Milwaukee, WI, 2014, pp. 445-450.

[22] K. Ogata, "Modern Control Engineering," Prentice Hall, 5th edition, 2010.

[23] M. Hlaili and H. Mechergui, "Comparison of Different MPPT Algorithms with a Proposed One Using a Power Estimator for Grid Connected PV Systems,” International Journal of Photoenergy, vol. 2016, pp. 1-10, 2016.

[24] B. S. Sotirios, et al., "ANN and Fuzzy Logic Controller Design for Hybrid Wind/PV System Connected to MV Distribution Grid," International Journal of Energy Sector Management, vol. 2, no. 4, pp. 499-520, 2008.

[25] S. O. Amrouche, et al., "Reactive Power Issues in Grid Connected Photovoltaic Systems," NuRER-4 International Conference on Nuclear and Renewable Energy Resources, Antalya, Turkey, 2014.

[26] C. Hicks, et al., "Power Quality of Residential PV System under Low Solar Irradiance and Off-Grid Operation," 2018 18th International Conference on Harmonics and Quality of Power (ICHQP), Ljubljana, 2018, pp. 1-5. 